\title{
Investigating the Role of Coolant and Lubricant Fluids on the Performance of Cutting Disks (Case Study: Hard Rocks)
}

The Mining-Geology-Petroleum Engineering Bulletin UDC: 622.7

DOI: $10.17794 / \operatorname{rgn} .2019 .2 .2$

Preliminary communication

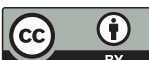

\author{
Seyed Mehdi Hosseini'; Mohammad Ataei'; Reza Khalokakaei;; \\ Reza Mikaeil'; Sina Shaffiee Haghshenas ${ }^{5}$ \\ ${ }^{I}$ Faculty of Mining, Petroleum \& Geophysics, Shahrood University of Technology, Shahrood, Iran \\ ${ }^{2}$ Faculty of Mining, Petroleum \& Geophysics, Shahrood University of Technology, Shahrood, Iran, orcid.org/0000-0002-7016-8170 \\ ${ }^{3}$ Faculty of Mining, Petroleum \& Geophysics, Shahrood University of Technology, Shahrood, Iran \\ ${ }^{4}$ Department of Mining and Metallurgical Engineering, Urmia University of Technology, Urmia, Iran, orcid.org/0000-0001-8404-3216 \\ ${ }^{5}$ Young Researchers and Elite Club, Rasht Branch, Islamic Azad University, Rasht, Iran, orcid.org/0000-0003-2859-3920
}

\begin{abstract}
The correct and proper selection of coolant and lubricant fluids in the dimension hard rocks' cutting process is one of the most important factors in the improvement of the cutting process, and in the increase of economic efficiency and quality of stone production. Therefore, this present study aims to study the role of coolant and lubricant fluids in the cutting performance of dimension hard rocks. In this study, 10 granite stone samples were collected from Iranian quarries and their physical and mechanical properties including their uniaxial compressive strength, Mohs hardness, Schimazek's F-abrasiveness factors and Young modulus were measured and determined. According to the three types of coolant and lubricant fluids, including the two types of soap water with ratios of 1 to 40 and 1 to 20 and one type of lubricant and coolant powder, and using two different operational parameters such as feed rate (Fr) and depth of cut (Dc), 16o laboratory tests for each of these fluids were studied and measured in order to determine the maximum electrical current consumed by the machine. The obtained results were statistically and intelligently evaluated and analyzed through the radial basis function (RBF). Based upon the results obtained from both the analytical methods, the lubricant and coolant powder with ratios of 1 to 20 had the maximum and minimum effects on the reduction of the maximum consumed electrical current in the hard rocks' cutting process.
\end{abstract}

Keywords:

Hard Rocks; Coolant and Lubricant Fluids; Cutting Process; Maximum Electrical Current; RBF

\section{Introduction}

Significant growth in the construction industry has increased the application of dimension stones and investment in this industry. Investors in sectors of quarries and rock cutting factories look for ways to reduce expenses and enhance the quality. Therefore, the reduction of energy consumption and improvement of the cutting process as the most influential factors in increasing the efficiency are the most important concerns of investors in the sectors of quarries and dimension stones. Thus, proper identification and understanding of the cutting process can have a key role in increasing the efficiency and quality of the processed product (Careddu et al., 2017a; Careddu et al., 2017b; Mikaeil et al., 2018a). In the cutting process, various factors influence the performance of cutting devices and the machine's consumed power. Coolant fluids and lubricants are two of the most effective factors in the cutting process, and se-

Corresponding author: Seyed Mehdi Hosseini

m_hosseini_uni@shahroodut.ac.ir lecting the proper type of these fluids can lead to a reduction in the consumed energy, improvement of the cutting process, and an increase in the quality of stone and longevity of the cutting device. In fact, coolant fluids and lubricants help mitigate thermal tensions. Inappropriate tension in the cutting process causes power fluctuations and chips which are the main factors in energy loss in the cutting process. Various studies have been conducted for reviewing the consumed electrical current and increasing the efficiency in the stones' cutting process (Balci \& Tumac, 2012; Tumac et al., 2016; Copur et al., 2017; Tumac et al., 2018; Mikaeil et al., 2018; Antoljak et al., 2018; Akhyani et al., 2018; Aryafar et al., 2018). In a study conducted by Ucun et al., alternative fluids for water in the natural stones' cutting process were investigated. In their study, water, AceCool, boron oil and liquid soap were used as coolant fluids, and two different natural stones were evaluated. The results obtained from this research showed superiority of other fluids over water in the cutting process, and in the meantime, a mixture of water and boron oil had the 
highest effect in increasing the efficiency of the cutting process (Ucun et al., 2012). In another study conducted by Mikaeil et al., using the harmony search algorithm (HAS), the cutting performance of the diamond wire saw was evaluated. In their study, the cutting performance was evaluated using the wear rate of the diamond wire saw. The final results indicated that the harmony search algorithm had a high capability in the identification of the cutting process and evaluation of the diamond wire saw's cutting performance (Mikaeil et al., 2016). In the study of Bai et al., using the integration of two distinctive multiple attribute decision making (MADM) techniques, the most appropriate cutting fluid was rated as the cleaner production. These research studies have been conducted on granite samples and finally the obtained results showed that the proposed decision method was used in the codification of instructions for proper selection of the cutting fluid as the cleaner production (Bai et al., 2018). A study was conducted by Mikaeil et al. for anticipating the performance of the cutting process based on the wear rate using techniques such as the adaptive neuro-fuzzy inference system (ANFIS) and a group method of data handling a type of neural network. Experiments were conducted on 38 stone samples extracted from Turkey quarries. The obtained results showed that the ANFIS-subtractive clustering method had the most capability in the performance evaluation of the diamond wire saw's cutting process in comparison to other methods (Mikaeil et al., 2018b). In the study of Dormishi et al., the cutting process was evaluated based on the anticipation of the maximum electrical current consumed by the cutting machine. The intelligent models of ANFIS-PSO and ANFIS-DE were used to provide a model and predict the consumed electrical current in order to evaluate the cutting performance. The result obtained from the research showed that intelligent techniques had a high ability to identify the cutting process and provide a dynamic model for anticipating the electrical current consumed by the cutting machine (Dormishi et al., 2018). In the study of Mikaeil et al., to evaluate and understand the cutting process of the circular saw machine, two soft computing methods including the imperialist competitive algorithm and the fuzzy clustering technique were used. In this study, 12 dimension stone block samples were used. The obtained results indicated the superiority of the imperialist competitive algorithm over the fuzzy clustering technique in understating and evaluating the performance of the machine based on the hourly production rates (Mikaeil et al., 2018c).

It is worth mentioning that although various studies were conducted for evaluating and investigating the cutting process and the electrical current consumed by the cutting machine, few studies addressed the effect of the coolant and lubricant fluids on the improvement of the cutting process and the reduction of the electrical current consumed by the cutting machine. The effect of the lubricant fluid on the cutting process is undeniable and through serious and planned studies, it is possible to achieve significant savings in energy consumption and cutting devices in the stone cutting industry. Thus, based upon the importance of the situation, in this study, first the laboratory sampling and investigation of the samples are addressed. Then, according to the three types of coolant and lubricant fluids, including the two types of soap water with ratios of 1 to 40 and 1 to 20 and one type of lubricant and coolant powder and with two different operational parameters such as the feed rate $(\mathrm{Fr})$ and depth of cut (Dc), 160 laboratory tests are conducted for each fluid in order to measure the electrical current consumed by the cutting machine. Finally, results are evaluated through analytical-statistical methods, including multivariate linear regression and the radial basis function (RBF) and the effect of each of the coolant and lubricant fluids on the performance of the cutting process is considered according to the consumed electrical current.

\section{Case Study}

In this study, 10 granite stone samples were collected from Iranian quarries, respectively, including Khorram Dareh granite, Birjand Gangali green granite, Naein Shadab green granite, Birjand Kahooei green granite, Natanz white granite, Nehbandan white granite, Isfahan red granite, Yazd red granite, Mashhad pearl granite, and Chayan black granite. In the next step, the collected samples were prepared for laboratory experiments and four physical and mechanical parameters of stones, including the uniaxial compressive strength, Mohs hardness, Schimazek's F-abrasiveness factors and Young modulus were tested and measured. In the final step, for measuring the maximum electrical current consumed by the disk cutting machine, three types of coolant and lubricant fluids were used, including two types of soap water with ratios of 1 to 40 and 2 to 20, and one type of lubricant and coolant powder, respectively. Table 1 and Figure 1 show the properties of fluids and the disk cutting machine used in this study, respectively.

Table 1: Properties of the coolant and lubricant fluids

\begin{tabular}{|l|c|c|c|}
\hline No. & Fluid & Viscosity $(\mathrm{mPa} \cdot \mathrm{s})$ & $\mathrm{PH}$ \\
\hline 1 & Soap water, 1 to 40 & $0 / 9851$ & 7.87 \\
\hline 2 & Soap water, 1 to 20 & $0 / 9754$ & 8.23 \\
\hline 3 & Lubricant \& Coolant powder & 1.839 & 7.96 \\
\hline
\end{tabular}

There are a lot of key purposes for using coolant and lubricant fluids such as coolant of the work and tool; enhancing dimensional stability (Boubekri \& Shaikh 2015). In this study, a major contribution of using these fluids is the investigation of the relationship between coolant and lubricant fluids and the maximum electrical current consumption. According to Table 1, the three types of coolant and lubricant fluids, namely the two 


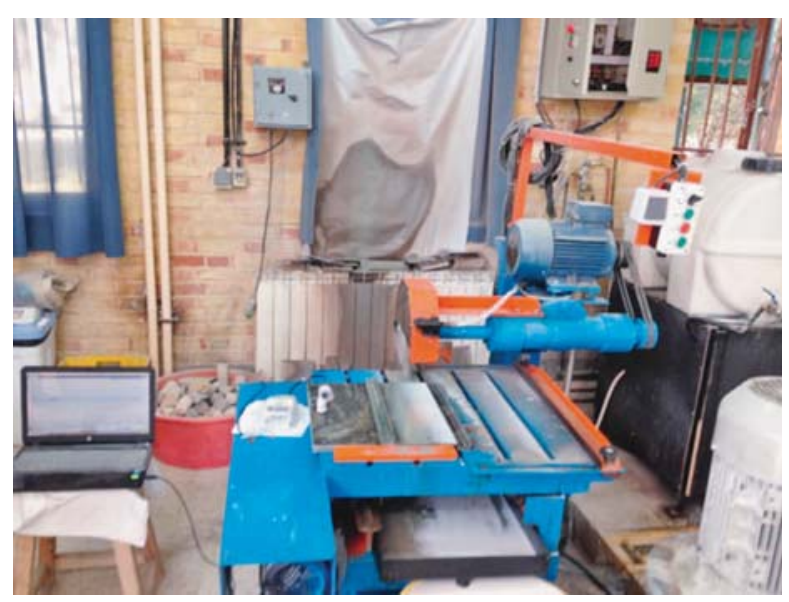

Figure 1: A view of the disk cutting machine at an experimental scale

types of soap water with ratios of 1 to 40 and 1 to 20 and one type of the lubricant and coolant powder were considered based upon the experiences of the research team and the common and available fluids on the market and industry.

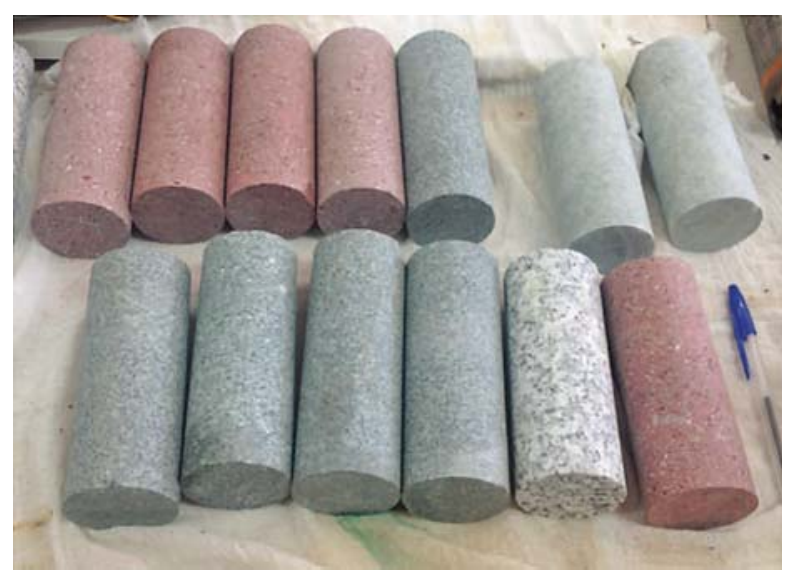

Figure 2: Some prepared samples
In the cutting process, the two different operational characteristics of the cutting machines, namely Fr (feed rate) and Dc (depth of cut) are often considered as a pair, because of their combined impact on the cutting process. Hence, according to two different operational characteristics of the cutting machines including Fr and Dc, the cutting machine conducted the experiments under different operational conditions with various depths of cutting of $0.5,0.7,1$ and $1.3(\mathrm{Cm})$ and different feed rates of 45 , 60,75 and $90(\mathrm{~cm} / \mathrm{min})$ with a fixed rotation of 3400 (round/min) of the disk, and for each fluid, 160 tests were conducted, and a total of 480 tests were performed for the three fluids. In addition, some important experimental parameters were the diameter and width of the disc, which equal $25(\mathrm{Cm})$ and $5(\mathrm{~mm})$, respectively. There were 18 diamond segments, each with a size of 35 $(\mathrm{mm}) \times 2.5(\mathrm{~mm}) \times 6.0(\mathrm{~mm})$. A maximum spindle motor power of $4(\mathrm{~kW})$ was used. The specimen dimensions were $40 \times 40 \times 2(\mathrm{Cm})$, and the cutting length was considered $40(\mathrm{Cm})$. Also, the coolant flow was water. In all cases, the maximum electrical current consumed by the machine during the cutting process was measured and recorded by an exact ammeter (considering the recording of changes in the machine's input current). It is worth noting that all of these experiments were done in the rock mechanic laboratory of Shahrood University of Technology and based on the ISRM international standards (ISRM 1981). The physical and mechanical characteristics and test results of one specific operating condition are shown in Table 2. In Figure 2, some prepared samples for testing are shown.

\section{Statistical Analysis}

One of fundamentals of any scientific study is the correct scientific research data process. There are different methods for the descriptive and statistical analyses among which the multivariate linear regression is one of the most complicated statistical techniques in the analysis, description and process of data and provision of a

Table 2: Physical and mechanical properties of rock samples and the results of one specific operating condition

\begin{tabular}{|l|l|c|c|c|c|c|c|c|c|c|}
\hline $\begin{array}{l}\text { Stones } \\
\text { Group }\end{array}$ & Commercial name & $\begin{array}{c}\text { SF-a } \\
(\mathrm{N} / \mathrm{mm})\end{array}$ & $\begin{array}{c}\mathrm{YM} \\
(\mathrm{GPa})\end{array}$ & $\mathrm{Mh}$ & $\begin{array}{c}\mathrm{UCS} \\
(\mathrm{MPa})\end{array}$ & $\begin{array}{c}\mathrm{Dc} \\
(\mathrm{Cm})\end{array}$ & $\begin{array}{c}\text { Fr } \\
(\mathrm{Cm} / \mathrm{min})\end{array}$ & $\begin{array}{c}\text { I (A) for } \\
\text { Soap Water } \\
\text { with ratios } \\
\text { of } 1 \text { to } 40\end{array}$ & $\begin{array}{c}\text { I (A) for } \\
\text { Soap Water } \\
\text { with ratios } \\
\text { of 1 to 20 }\end{array}$ & $\begin{array}{c}\text { I (A) for } \\
\text { Lubricant } \\
\text { \& Coolant } \\
\text { powder }\end{array}$ \\
\hline Granite & Khorram Dareh granite & 10.42 & 28.9 & 5.65 & 133 & 0.5 & 90 & 5.9 & 6.1 & 5.5 \\
\hline Syenite & Birjand Gangali green granite & 28.3 & 52 & 6.4 & 239 & 0.5 & 90 & 6.1 & 6.7 & 5.1 \\
\hline Diabase & Naein Shadab green granite & 8.352 & 56 & 6.1 & 279 & 0.5 & 90 & 5.9 & 6.4 & 6.4 \\
\hline Granite & Birjand Kahooei green granite & 4.284 & 37 & 6.3 & 110 & 0.5 & 90 & 5.8 & 5.8 & 7.4 \\
\hline Granite & Natanz white granite & 46.63 & 43 & 5.7 & 150 & 0.5 & 90 & 5.8 & 5.8 & 6.1 \\
\hline Granite & Nehbandan white granite & 24.25 & 35.5 & 5.95 & 145 & 0.5 & 90 & 5.5 & 5.8 & 6.7 \\
\hline Tuff & Isfahan red granite & 1.872 & 46.5 & 6 & 182 & 0.5 & 90 & 6.1 & 6.3 & 6.1 \\
\hline Basalt & Yazd red granite & 14.24 & 43.6 & 6.1 & 142 & 0.5 & 90 & 6.4 & 6 & 6.9 \\
\hline Granite & Mashhad pearl granite & 8.5 & 31.2 & 5.6 & 125 & 0.5 & 90 & 5.5 & 6.5 & 5.5 \\
\hline Diorite & Chayan black granite & 7.6 & 48.6 & 6.6 & 173 & 0.5 & 90 & 5.8 & 6 & 6.1 \\
\hline
\end{tabular}


highly precise prediction model. Therefore, in this study, the application of the multivariate linear regression method for data analysis is addressed, and a model with a high ability in the prediction of the consumed electrical current is proposed. Before conducting the regression analyses for the data, it is necessary to study the parametric correlation of every independent variable (Ivšinović 2018; Feng et al., 2018). In this study, in order to study the parametric correlations of 6 input data (independent variables), although, there are some approaches to determine the correlation coefficient, based upon the number of data set and a measure of the linear correlation between two variables, the Pearson method is used. Equations 1 to 4 show the mathematical relations of the Pearson correlation coefficient.

$$
\begin{gathered}
\rho=r=\frac{S P_{D x y}}{\sqrt{S S_{X} \cdot S S_{Y}}} \\
S P_{D x y}=\sum x y-\frac{\left(\sum x\right)\left(\sum y\right)}{n} \\
S P_{X}=\sum_{i}^{n} x_{i}^{2}-\frac{\left(\sum x_{i}\right)^{2}}{n} \\
S P_{Y}=\sum_{i}^{n} y_{i}^{2}-\frac{\left(\sum y_{i}\right)^{2}}{n}
\end{gathered}
$$

While the Pearson correlation coefficient is determined by $\mathrm{r}$ or $\mathrm{p} . \mathrm{x}$ and $\mathrm{y}$ are two independent parameters, respectively which are in the interval of $1+$ and $1-$. A negative sign shows a reverse relation and a positive sign indicates a direct relation between the two independent parameters. For interpreting the correlation between these two independent parameters, the absolute value of these coefficients are used. The closer these correlation coefficients are to unity, the higher the correlation, and the closer these correlation coefficients are to zero, the lower the correlation between these two variables. The Pearson correlation coefficient is also called the Pearson product-moment correlation coefficient or the bilateral correlation coefficient. After measuring the data obtained from the laboratory experiments, in the first step, using the statistical package for social sciences (SPSS), data was studied for the purpose of the Pearson correlation coefficient analysis and study in order to determine the adaptability of the independent variables, including four mechanical and physical parameters including the uniaxial compressive strength, Mohs hardness, Schimazek's F-abrasiveness factors and Young modulus and two operational parameters of the machine, including Fr and Dc. The results are shown in Table 3.

The important point in the study of the $p$ value is that if $|\rho|>0.85$, then the correlation is considered to be strong, which according to the results obtained from Table 3 , the $\rho$ value is acceptable for all the cases. Although
Table 3: Correlation Coefficients between Various Factors

\begin{tabular}{|l|c|c|c|c|c|c|}
\hline & SF-a & YM & Mh & UCS & Dc & Fr \\
\hline SF-a & 1 & 0.077 & -0.219 & 0.043 & 0 & 0 \\
\hline YM & 0.077 & 1 & 0.632 & 0.855 & 0 & 0 \\
\hline Mh & -0.219 & 0.632 & 1 & 0.369 & 0 & 0 \\
\hline UCS & 0.043 & 0.855 & 0.369 & 1 & 0 & 0 \\
\hline Dc & 0 & 0 & 0 & 0 & 1 & 0 \\
\hline Fr & 0 & 0 & 0 & 0 & 0 & 1 \\
\hline
\end{tabular}

the $\rho$ value between USC and YM is equal to 0.855 , considering the nature of these parameters, this value can be ignored, and all of the independent parameters have a desired and proper correlation in order to study the dependent variable. Furthermore, the $\rho$ value between the stones' physical and mechanical independent variables and the machine's operational parameters obviously confirm that these 6 parameters have enough significance and desirability for analyzing and studying data by using the multivariate linear regression technique.

\subsection{Multivariate Linear Regression}

As mentioned before, the multivariate linear regression technique is one of the most appropriate methods in data analysis and provision of a proper model for predicting data. In this step, considering different electrical current obtained from the experiments using three different types of fluids, one prediction model was provided for each model, and the related analyses were done. For the entry of independent variables, "the enter method" was used because in this method, all of the independent variables were simultaneously entered in the model to determine the effect of all of the significant and non-significant variables on the dependent variable. Table 4 shows the values obtained from these analyses.

Where, the Std.Error of estimate shows the prediction power of the regression equation which is acceptable for all of the three models according to the results of Table 4. The $f$ value shows whether the obtained regression model is a good model or not, and is equal to dividing the average regression squares by the means residual squares. In fact, this parameter shows the ability of the independent variables in explaining the dependent variable, which in all of the three models, the obtained $\mathrm{f}$ value shows the efficacy and ability of variables in describing the maximum consumed electrical current as the dependent variable. Additionally, the beta parameter determines the relative proportion of each dependent variable in specifying the changes in the dependent variable. For example, Dc as one of the 6 dependent variables in this study with values of 0.797 and 0.706 had the highest effect on the maximum consumed electrical current (the dependent variable) in models 1 and 2, respectively. This means that by increasing or reducing one standard deviation, the standard deviation of the maximum consumed electrical current (the dependent varia- 
Table 4: Statistical analysis for the three coolant and lubricant fluids

\begin{tabular}{|c|c|c|c|c|c|c|c|}
\hline Models & \multicolumn{2}{|c|}{ B } & Std.Error & Beta & $\mathrm{R}^{2}$ & $\begin{array}{l}\text { Std.Error } \\
\text { of Estimate }\end{array}$ & $\mathrm{F}$ \\
\hline \multirow{7}{*}{$\begin{array}{l}\text { The First model } \\
\text { with Soap Water } \\
\text { with ratios of } 1 \\
\text { to } 40\end{array}$} & Constant & 0.781 & 0.85 & & \multirow{7}{*}{0.777} & \multirow{7}{*}{0.42} & \multirow{7}{*}{88.951} \\
\hline & SF-a & 0.002 & 0.003 & 0.024 & & & \\
\hline & YM & 0.016 & 0.011 & 0.152 & & & \\
\hline & $\mathrm{Mh}$ & 0.366 & 0.165 & 0.132 & & & \\
\hline & UCS & -0.001 & 0.001 & -0.037 & & & \\
\hline & Dc & 2.294 & 0.11 & 0.797 & & & \\
\hline & $\mathrm{Fr}$ & 0.015 & 0.002 & 0.296 & & & \\
\hline \multirow{7}{*}{$\begin{array}{l}\text { The Second } \\
\text { model with Soap } \\
\text { Water with ratios } \\
\text { of } 1 \text { to } 20\end{array}$} & Constant & 1.464 & 0.661 & & \multirow{7}{*}{0.863} & \multirow{7}{*}{0.327} & \multirow{7}{*}{161.04} \\
\hline & SF-a & -0.006 & 0.002 & -0.086 & & & \\
\hline & YM & -0.001 & 0.008 & -0.007 & & & \\
\hline & $\mathrm{Mh}$ & 0.143 & 0.129 & 0.052 & & & \\
\hline & UCS & 0.004 & 0.001 & 0.245 & & & \\
\hline & $\mathrm{Dc}$ & 2.016 & 0.085 & 0.706 & & & \\
\hline & $\mathrm{Fr}$ & 0.028 & 0.002 & 0.537 & & & \\
\hline \multirow{7}{*}{$\begin{array}{l}\text { The Third model } \\
\text { with Lubricant } \\
\& \text { Coolant } \\
\text { powder }\end{array}$} & Constant & 3.352 & 1.302 & & \multirow{7}{*}{0.726} & \multirow{7}{*}{0.645} & \multirow{7}{*}{67.525} \\
\hline & SF-a & -0.013 & 0.004 & -0.145 & & & \\
\hline & YM & 0.066 & 0.016 & 0.465 & & & \\
\hline & $\mathrm{Mh}$ & -0.226 & 0.253 & -0.059 & & & \\
\hline & UCS & -0.015 & 0.002 & -0.609 & & & \\
\hline & Dc & 2.343 & 0.168 & 0.59 & & & \\
\hline & $\mathrm{Fr}$ & 0.037 & 0.003 & 0.515 & & & \\
\hline
\end{tabular}

$\mathrm{B}=$ Constant and Independent Variables $(\mathrm{SF}-\mathrm{a}, \mathrm{YM}, \mathrm{Mh}, \mathrm{UCS}, \mathrm{Dc}, \mathrm{Fr})$; Beta= Standardized coefficients; $\mathrm{R}^{2}=$ Coefficients of Determination

ble) in model 1 was increased or reduced to the value of 0.797 , respectively. The beta value for UCS as another dependent variable in model 1 was equal to -0.037 , meaning that UCS had a negative and reverse effect on the maximum consumed electrical current in model 1. It is worth mentioning that the more independent the value of the beta coefficient is, the greater its role in changing the dependent variable. According to the results of Table 4, equations 5 to 7 calculated the multivariate linear equation for anticipating the maximum electrical current consumed by the machine for the two types of soap water with ratios of 1 to 40 and 2 to 20, and one type of lubricant and coolant powder, respectively.

$$
\begin{gathered}
\mathrm{I}=0.781+0.002 \mathrm{SFa}+0.016 \mathrm{YM}+0.366 \mathrm{Mh}- \\
-0.001 \mathrm{UCS}+2.294 \mathrm{Dc}+0.015 \mathrm{Fr} \\
\mathrm{I}=1.464-0.006 \mathrm{SFa}-0.001 \mathrm{YM}+0.143 \mathrm{Mh}+ \\
+0.004 \mathrm{UCS}+2.016 \mathrm{Dc}+0.028 \mathrm{Fr} \\
\mathrm{I}=3.352-0.013 \mathrm{SFa}+0.066 \mathrm{YM}-0.226 \mathrm{Mh}- \\
-0.015 \mathrm{UCS}+2.343 \mathrm{Dc}+0.0375 \mathrm{Fr}
\end{gathered}
$$

According to the value $\mathrm{R}^{2}$ obtained for each model, it is completely clear that the second model with a value of $\mathrm{R}^{2}=0.863$ has a better prediction power compared to the two other models. In addition, Figure 3 shows the regression diagram between the maximum consumed electrical current measured and predicted.

According to the results of Table 4 and Figure 3, it is completely clear that the maximum consumed electrical current when using the lubricant and coolant powder as the coolant and lubricant fluids in the cutting machine was reduced and this fluid as an influential and desired factor could play an effective role in the reduction of energy consumed by the machine.

\section{Radial Basis Function (RBF) Neural Networks}

In the area of computational intelligence, there are numerous efficient and intelligent methods and optimizations for solving complicated and dynamic problems such as heuristic and meta-heuristic algorithms, fuzzy logic, and artificial neural networks which are undoubtedly the most important components in the computational intelligence of artificial neural networks (Fathabadi \& Khodaei, 2012). Artificial neural networks have various applications in solving complicated problems and uncertainty (Rad et al., 2012; Rad et al., 2014; Manouchehrian et al., 2014; Faradonbeh et al., 2016; Sabzi et al., 2016; Khandelwal et al., 2016; Sabzi et al., 2017; Hoseinian et al., 2017; Darbor et al., 2017; 


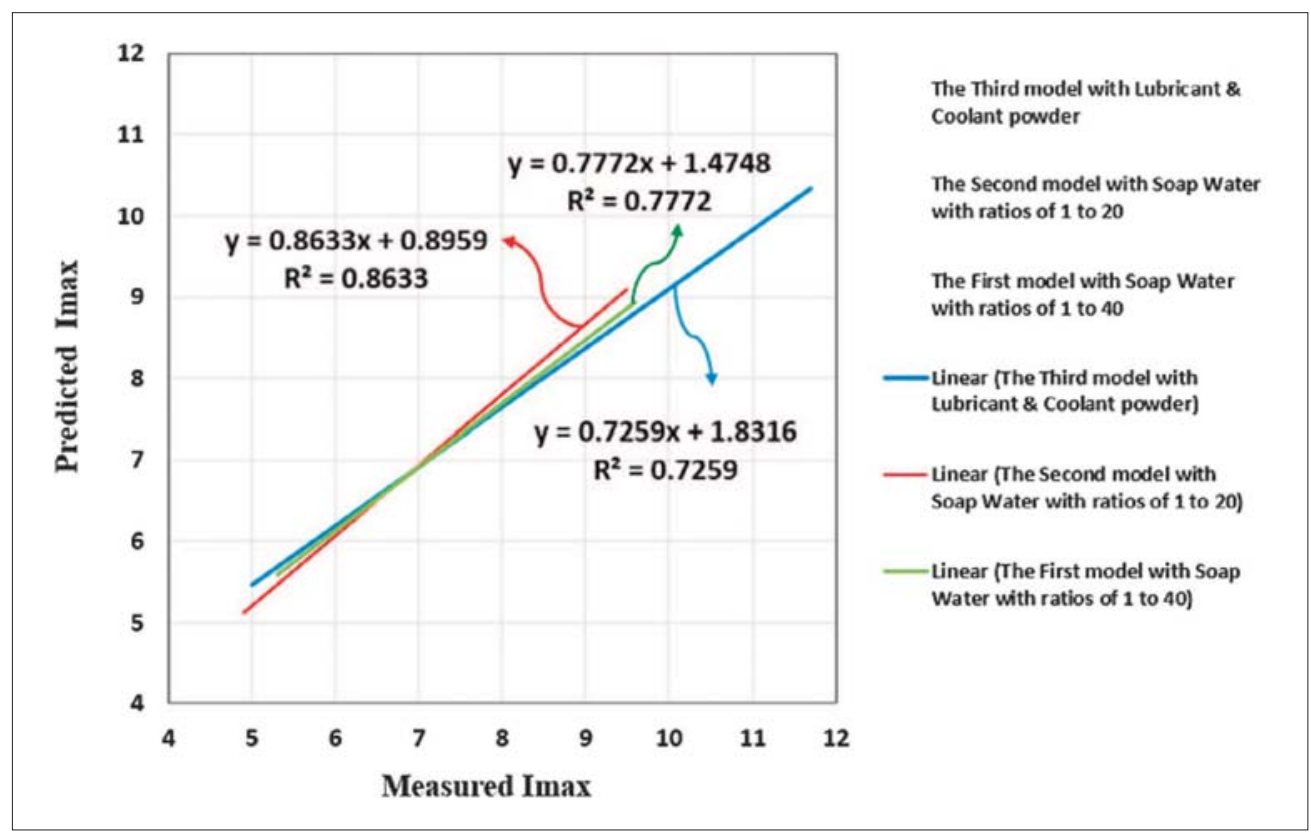

Figure 3: Comparison between the linear regressions of models

Mahdevari et al., 2017; Khandelwal et al., 2017; Sharifzadeh 2017; Faradonbeh \& Taheri, 2018; Salemi et al., 2018; Ocak et al., 2018). In this study conducted by Armaghani et al. on blasting operations, using the imperialist competitive algorithm (ICA), the training of neural networks for anticipating air-overpressure resulting from blasting was addressed. Studies were done on 70 blasting operations and the results showed the efficiency of the hybrid imperialist competitive algorithm (ICA)-ANN for anticipating the air-overpressure compared to other empirical methods (Armaghani et al., 2016). The wear rate of a diamond wire saw was studied by Mikaeil et al. using artificial neural networks. In their study, the wear rate of a diamond wire saw was investigated for 38 different rocks including andesites, limestones and real marbles from quarries located in eleven areas in Turkey. Their obtained results showed the efficiency of artificial neural networks in providing an optimized model for predicting the wear rate (Mikaeil et al., 2017). In the study of Mohammadi et al., a neural model was proposed for anticipating the production rate of a chain saw machine using the Perceptron multilayer neural networks. By conducting 98 laboratory tests on the stone samples extracted from Iranian quarries, 4 measured parameters including uniaxial compressive strength (UCS), Los Angeles abrasion (LAA) Test, equivalent quartz content (Qc), and Schmidt Hammer (Sch) were considered as the model's input data and the production rate as the output data. According to the final results, the proposed model had the highest efficiency in anticipating the production rate of a chain saw machine (Mohammadi et al., 2018).

The RBF neural network is one of the most widely used neural networks which has a high convergence speed compared to multilayered networks and conducts many searches in different technical-engineering areas. $\mathrm{RBF}$ is a type of feedforward network and creating the most optimal mapping between the input and output vectors is the most common objective of this network (Er et al., 2002; Strumilło et al., 2003). In terms of layers' structures, it is similar to the perceptron neural network and is composed of three layers, including the input layer, the hidden layer and the output layer, respectively. The hidden layer is responsible for creating mapping between the input and output data. The input and output layers are responsible for the entry and exit of data, respectively, and finally, the output data of a simple weight set is linear. In addition, one of the most important differences between the RBF and perceptron neural network is the number of layers, i.e. the number of layers in the perceptron neural network can be three or more, but in the RBF it is just three. The argument of functions is in the Euclidean distance, while in the perceptron neural network, it is the product of internal multiplication of the input vector of layer by the weights (Yingwei et al., 1998; Karayiannis \& Behnke 2018; Mirjalili 2019). One of the reasons for such popularity and capability in this network is the fact that due to having a high enough number of neurons in the hidden layer, it can estimate each continuous function with any degree of precision. Figure 4 shows the basic architecture of this network.

Given the high optimum capability of the RBF neural network in facing with complicated problems, in this study this technique is used for investigating the effect of different coolant and lubricant fluids on the performance of a machine and the consumed electrical current, and also for providing models for predicting the electri- 


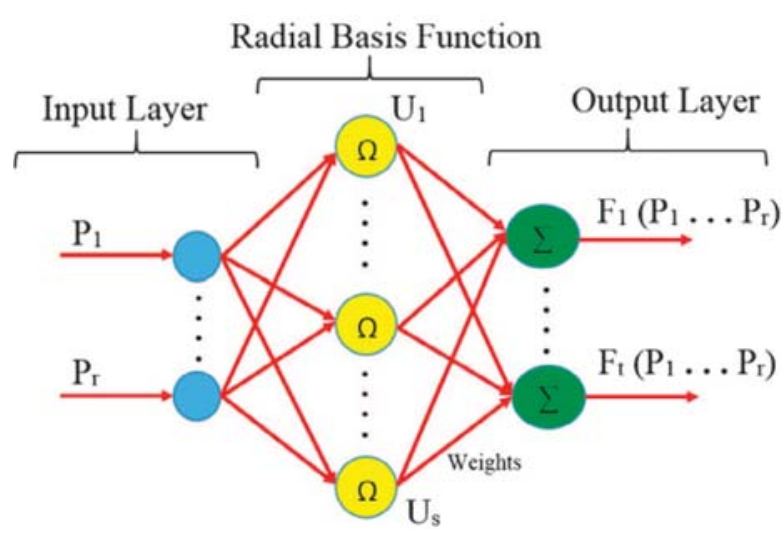

Figure 4: Architecture of radial basis function (RBF) neural network

cal current consumed by the cutting machine. To ensure the efficacy of the algorithm in this study, three performance indices of the root mean square error (RMSE), value account for (VAF) and correlation coefficient $\left(\mathrm{R}^{2}\right)$ are used according to equations 8 to $\mathbf{1 0}$.

$$
\begin{gathered}
R M S E=\sqrt{\frac{1}{n} \sum_{i=1}^{n}\left(x_{i}-y_{i}\right)^{2}} \\
V A F=\left[1-\frac{\operatorname{var}\left(x_{i}-y_{i}\right)}{\operatorname{var}\left(x_{i}\right)}\right] \\
R^{2}=\frac{\left[\sum_{i=1}^{n}\left(x_{i}-x_{\text {mean }}\right)^{2}\right]-\left[\sum_{i=1}^{n}\left(x_{i}-y_{i}\right)^{2}\right]}{\left[\sum_{i=1}^{n}\left(x_{i}-x_{\text {mean }}\right)^{2}\right]}
\end{gathered}
$$

Where, $x_{i}$ and $y_{i}$ are the measured and predicted values of output data, respectively and $n$ is the number of data sets. In order to achieve the highest desirability in the neural network computations, the performance indices must be at their highest points, i.e. 1, 100 and 0 for $\mathrm{R}^{2}$, VAF and RMSE, respectively.

\subsection{Modelling Using RBF}

As mentioned before, the RBF neural network is one of the most efficient and desirable intelligent methods in

Table 5: The effects of control parameters on the statistical functions' performance of models with soap water with ratios of 1 to 40

\begin{tabular}{|l|c|c|c|c|c|c|c|c|c|}
\hline \multirow{2}{*}{$\begin{array}{l}\text { Model } \\
\text { No. }\end{array}$} & \multirow{2}{*}{$\begin{array}{c}\text { Layer } \\
\text { Size }\end{array}$} & \multirow{2}{*}{ Spread } & \multirow{2}{*}{$\begin{array}{c}\text { The Number } \\
\text { of Neuron }\end{array}$} & \multicolumn{2}{|c|}{$\begin{array}{c}\text { The Results of Network } \\
\text { for R }\end{array}$} & \multicolumn{2}{|c|}{$\begin{array}{c}\text { The Results of Network } \\
\text { for RMSE }\end{array}$} & \multicolumn{2}{|c|}{$\begin{array}{c}\text { The Results of Network } \\
\text { for VAF }\end{array}$} \\
\cline { 5 - 11 } & & & & Train & Test & Train & Test & Train & Test \\
\hline 1 & 3 & 0.5 & 90 & 0.95 & 0.22 & 0.18 & 0.86 & 95.64 & 15.34 \\
\hline 2 & 3 & 0.5 & 100 & 0.97 & 0.24 & 0.14 & 0.82 & 97.19 & 17.89 \\
\hline 3 & 3 & 0.5 & 110 & 0.99 & 0.50 & 0.04 & 0.72 & 99.65 & 47.91 \\
\hline 4 & 3 & 1 & 90 & 0.93 & 0.20 & 0.22 & 1.08 & 92.85 & 14.23 \\
\hline 5 & 3 & 1 & 100 & 0.99 & 0.25 & 0.06 & 0.92 & 99.42 & 20.76 \\
\hline 6 & 3 & 1 & 110 & 0.99 & 0.29 & 0.05 & 0.99 & 99.61 & 18.44 \\
\hline 7 & 3 & 1.5 & 90 & 0.98 & 0.46 & 0.09 & 0.72 & 98.66 & 23.33 \\
\hline 8 & 3 & 1.5 & 100 & 0.99 & 0.81 & 0.03 & 0.46 & 99.85 & 81.01 \\
\hline 9 & 3 & 1.5 & 110 & 0.99 & 0.69 & 0.03 & 0.48 & 99.73 & 63.37 \\
\hline
\end{tabular}

\begin{tabular}{|c|c|c|c|c|c|c|c|c|c|}
\hline \multirow{2}{*}{$\begin{array}{l}\text { Model } \\
\text { No. }\end{array}$} & \multirow{2}{*}{$\begin{array}{l}\text { Layer } \\
\text { Size }\end{array}$} & \multirow{2}{*}{ Spread } & \multirow{2}{*}{$\begin{array}{l}\text { The Number } \\
\text { of Neuron }\end{array}$} & \multicolumn{2}{|c|}{$\begin{array}{l}\text { The Results of Network } \\
\text { for } \mathrm{R}^{2}\end{array}$} & \multicolumn{2}{|c|}{$\begin{array}{l}\text { The Results of Network } \\
\text { for RMSE }\end{array}$} & \multicolumn{2}{|c|}{$\begin{array}{l}\text { The Results of Network } \\
\text { for VAF }\end{array}$} \\
\hline & & & & Train & Test & Train & Test & Train & Test \\
\hline 1 & 3 & 0.5 & 90 & 0.97 & 0.57 & 0.14 & 0.62 & 97.12 & 28.92 \\
\hline 2 & 3 & 0.5 & 100 & 0.98 & 0.46 & 0.09 & 0.66 & 98.93 & 36.37 \\
\hline 3 & 3 & 0.5 & 110 & 0.99 & 0.28 & 0.02 & 1.57 & 99.88 & 27.49 \\
\hline 4 & 3 & 1 & 90 & 0.98 & 0.47 & 0.09 & 0.75 & 98.78 & 30.86 \\
\hline 5 & 3 & 1 & 100 & 0.99 & 0.31 & 0.05 & 0.93 & 99.65 & 25.59 \\
\hline 6 & 3 & 1 & 110 & 0.99 & 0.22 & 0.02 & 0.88 & 99.92 & 18.37 \\
\hline 7 & 3 & 1.5 & 90 & 0.93 & 0.54 & 0.21 & 0.67 & 93.41 & 37.93 \\
\hline 8 & 3 & 1.5 & 100 & 0.99 & 0.82 & 0.01 & 0.44 & 99.95 & 81.99 \\
\hline 9 & 3 & 1.5 & 110 & 0.99 & 0.79 & 0.02 & 0.47 & 99.88 & 79.41 \\
\hline
\end{tabular}

Table 6: The effects of control parameters on the statistical functions' performance of models with soap water with ratios of 1 to 20 
Table 7: The effects of control parameters on the statistical functions' performance of models with lubricant \& coolant powder

\begin{tabular}{|l|c|c|c|c|c|c|c|c|c|}
\hline \multirow{2}{*}{$\begin{array}{l}\text { Model } \\
\text { No. }\end{array}$} & \multirow{2}{*}{$\begin{array}{c}\text { Layer } \\
\text { Size }\end{array}$} & \multirow{2}{*}{ Spread } & \multirow{2}{*}{$\begin{array}{c}\text { The Number } \\
\text { of Neuron }\end{array}$} & \multicolumn{2}{|c|}{$\begin{array}{c}\text { The Results of Network } \\
\text { for R }\end{array}$} & \multicolumn{2}{|c|}{$\begin{array}{c}\text { The Results of Network } \\
\text { for RMSE }\end{array}$} & \multicolumn{2}{|c|}{$\begin{array}{c}\text { The Results of Network } \\
\text { for VAF }\end{array}$} \\
\cline { 6 - 11 } & & & & Train & Test & Train & Test & Train & Test \\
\hline 1 & 3 & 0.5 & 90 & 0.96 & 0.47 & 0.25 & 0.87 & 95.85 & 35.05 \\
\hline 2 & 3 & 0.5 & 100 & 0.99 & 0.62 & 0.11 & 0.73 & 99.17 & 51.07 \\
\hline 3 & 3 & 0.5 & 110 & 0.99 & 0.23 & 0.03 & 1.66 & 99.93 & 21.87 \\
\hline 4 & 3 & 1 & 90 & 0.98 & 0.51 & 0.15 & 0.96 & 98.55 & 48.84 \\
\hline 5 & 3 & 1 & 100 & 0.99 & 0.59 & 0.04 & 0.99 & 99.87 & 59.81 \\
\hline 6 & 3 & 1 & 110 & 0.99 & 0.81 & 0.04 & 0.58 & 99.85 & 75.28 \\
\hline 7 & 3 & 1.5 & 90 & 0.99 & 0.63 & 0.06 & 0.79 & 99.73 & 55.02 \\
\hline 8 & 3 & 1.5 & 100 & 0.99 & 0.82 & 0.03 & 0.54 & 99.95 & 81.95 \\
\hline 9 & 3 & 1.5 & 110 & 0.99 & 0.74 & 0.03 & 0.63 & 99.91 & 66.49 \\
\hline
\end{tabular}

Table 8: Ranking of each model of soap water with ratios of 1 to 40 using RBF network

\begin{tabular}{|c|c|c|c|c|c|c|c|c|c|c|}
\hline \multirow{2}{*}{$\begin{array}{l}\text { Model } \\
\text { No. }\end{array}$} & \multirow{2}{*}{$\begin{array}{l}\text { Layer } \\
\text { Size }\end{array}$} & \multirow{2}{*}{ Spread } & \multirow{2}{*}{$\begin{array}{l}\text { The Number } \\
\text { of Neuron }\end{array}$} & \multicolumn{2}{|c|}{$\begin{array}{l}\text { The Results of } \\
\text { Network for } \mathrm{R}^{2}\end{array}$} & \multicolumn{2}{|c|}{$\begin{array}{c}\text { The Results of } \\
\text { Network for RMSE }\end{array}$} & \multicolumn{2}{|c|}{$\begin{array}{c}\text { The Results of } \\
\text { Network for VAF }\end{array}$} & \multirow{2}{*}{ Total Rank } \\
\hline & & & & Train & Test & Train & Test & Train & Test & \\
\hline 1 & 3 & 0.5 & 90 & 6 & 2 & 3 & 5 & 2 & 2 & 20 \\
\hline 2 & 3 & 0.5 & 100 & 7 & 3 & 4 & 6 & 3 & 3 & 26 \\
\hline 3 & 3 & 0.5 & 110 & 9 & 7 & 8 & 7 & 7 & 7 & 45 \\
\hline 4 & 3 & 1 & 90 & 5 & 1 & 2 & 2 & 1 & 1 & 12 \\
\hline 5 & 3 & 1 & 100 & 9 & 4 & 6 & 4 & 5 & 5 & 33 \\
\hline 6 & 3 & 1 & 110 & 9 & 5 & 7 & 3 & 6 & 4 & 34 \\
\hline 7 & 3 & 1.5 & 90 & 8 & 6 & 5 & 7 & 4 & 6 & 36 \\
\hline 8 & 3 & 1.5 & 100 & 9 & 9 & 9 & 9 & 9 & 9 & 54 \\
\hline 9 & 3 & 1.5 & 110 & 9 & 8 & 9 & 8 & 8 & 8 & 50 \\
\hline
\end{tabular}

Table 9: Ranking of each model of soap water with ratios of 1 to 20 using RBF network

\begin{tabular}{|c|c|c|c|c|c|c|c|c|c|c|}
\hline \multirow{2}{*}{$\begin{array}{l}\text { Model } \\
\text { No. }\end{array}$} & \multirow{2}{*}{$\begin{array}{l}\text { Layer } \\
\text { Size }\end{array}$} & \multirow{2}{*}{ Spread } & \multirow{2}{*}{$\begin{array}{l}\text { The Number } \\
\text { of Neuron }\end{array}$} & \multicolumn{2}{|c|}{$\begin{array}{l}\text { The Results of } \\
\text { Network for } \mathrm{R}^{2}\end{array}$} & \multicolumn{2}{|c|}{$\begin{array}{c}\text { The Results of } \\
\text { Network for RMSE }\end{array}$} & \multicolumn{2}{|c|}{$\begin{array}{c}\text { The Results of } \\
\text { Network for VAF }\end{array}$} & \multirow{2}{*}{ Total Rank } \\
\hline & & & & Train & Test & Train & Test & Train & Test & \\
\hline 1 & 3 & 0.5 & 90 & 7 & 7 & 5 & 7 & 3 & 4 & 33 \\
\hline 2 & 3 & 0.5 & 100 & 8 & 5 & 6 & 6 & 5 & 6 & 36 \\
\hline 3 & 3 & 0.5 & 110 & 9 & 3 & 8 & 1 & 7 & 3 & 31 \\
\hline 4 & 3 & 1 & 90 & 8 & 6 & 6 & 4 & 4 & 5 & 33 \\
\hline 5 & 3 & 1 & 100 & 9 & 4 & 7 & 2 & 6 & 2 & 30 \\
\hline 6 & 3 & 1 & 110 & 9 & 2 & 8 & 3 & 8 & 1 & 31 \\
\hline 7 & 3 & 1.5 & 90 & 6 & 6 & 4 & 5 & 2 & 7 & 30 \\
\hline 8 & 3 & 1.5 & 100 & 9 & 9 & 9 & 9 & 9 & 9 & 54 \\
\hline 9 & 3 & 1.5 & 110 & 9 & 8 & 8 & 8 & 7 & 8 & 48 \\
\hline
\end{tabular}

modeling industrial and scientific phenomena. Therefore, in this section, various neural models are used for determining the most appropriate model for the anticipation of the maximum electrical current consumed by the cutting machine for hard rocks under the three different fluids. For modelling, firstly, the RBF control parame- ters are determined. These control parameters play a significant role in the convergence speed and improvement of the algorithm's performance. Two important control parameters in the RBF neural networks include the number of hidden layer neurons and spread and these hidden layer neurons are responsible for connecting and deter- 
Table 1o: Ranking of each model of lubricant \& coolant powder using RBF network

\begin{tabular}{|c|c|c|c|c|c|c|c|c|c|c|}
\hline \multirow{2}{*}{$\begin{array}{l}\text { Model } \\
\text { No. }\end{array}$} & \multirow{2}{*}{$\begin{array}{l}\text { Layer } \\
\text { Size }\end{array}$} & \multirow{2}{*}{ Spread } & \multirow{2}{*}{$\begin{array}{l}\text { The Number } \\
\text { of Neuron }\end{array}$} & \multicolumn{2}{|c|}{$\begin{array}{l}\text { The Results of } \\
\text { Network for } \mathrm{R}^{2}\end{array}$} & \multicolumn{2}{|c|}{$\begin{array}{l}\text { The Results of } \\
\text { Network for RMSE }\end{array}$} & \multicolumn{2}{|c|}{$\begin{array}{l}\text { The Results of } \\
\text { Network for VAF }\end{array}$} & \multirow{2}{*}{ Total Rank } \\
\hline & & & & Train & Test & Train & Test & Train & Test & \\
\hline 1 & 3 & 0.5 & 90 & 7 & 2 & 4 & 4 & 1 & 2 & 20 \\
\hline 2 & 3 & 0.5 & 100 & 9 & 5 & 6 & 6 & 3 & 4 & 33 \\
\hline 3 & 3 & 0.5 & 110 & 9 & 1 & 9 & 1 & 8 & 1 & 29 \\
\hline 4 & 3 & 1 & 90 & 8 & 3 & 5 & 3 & 2 & 3 & 24 \\
\hline 5 & 3 & 1 & 100 & 9 & 4 & 8 & 2 & 6 & 6 & 35 \\
\hline 6 & 3 & 1 & 110 & 9 & 8 & 8 & 8 & 5 & 8 & 46 \\
\hline 7 & 3 & 1.5 & 90 & 9 & 6 & 7 & 5 & 4 & 5 & 36 \\
\hline 8 & 3 & 1.5 & 100 & 9 & 9 & 9 & 9 & 9 & 9 & 54 \\
\hline 9 & 3 & 1.5 & 110 & 9 & 7 & 9 & 7 & 7 & 7 & 46 \\
\hline
\end{tabular}

mining the performance of functions in the hidden layer, and spread is the controller of dispersion in functions. In order to determine these control parameters exactly, trial and error must be done. Therefore, based on the opinions of experts and professionals in the area of soft computing and considering the input data, the number of neurons in the hidden layers is considered to be 90, 100 and 110 and the respected values are $0.5,1$ and 1.5 , respectively. The input and output data are used based on Looney's research studies as $0.75 \%$ for training data and the rest for the test data (Looney 1996). Modellings for the experimental results are done based on the three desired fluids and 9 models for each fluid and a total of 27 models are simulated, respectively. Tables 5 to 7 show
Table 11: Comparison of the results of models among the three coolant and lubricant fluids using RBF

\begin{tabular}{|l|c|c|c|}
\hline Models & $\begin{array}{c}\text { The Results } \\
\text { of Network } \\
\text { for R }{ }^{2}\end{array}$ & $\begin{array}{c}\text { The Results } \\
\text { of Network } \\
\text { for RMSE }\end{array}$ & $\begin{array}{c}\text { The Results } \\
\text { of Network } \\
\text { for VAF }\end{array}$ \\
\hline $\begin{array}{l}\text { The model with } \\
\text { Soap Water with } \\
\text { ratios of 1 to 40 }\end{array}$ & 0.857 & 0.345 & 85.31 \\
\hline $\begin{array}{l}\text { The model with } \\
\text { Soap Water with } \\
\text { ratios of 1 to 20 }\end{array}$ & 0.895 & 0.285 & 89.16 \\
\hline $\begin{array}{l}\text { The model with } \\
\text { Lubricant \& } \\
\text { Coolant powder }\end{array}$ & 0.793 & 0.572 & 77.82 \\
\hline
\end{tabular}

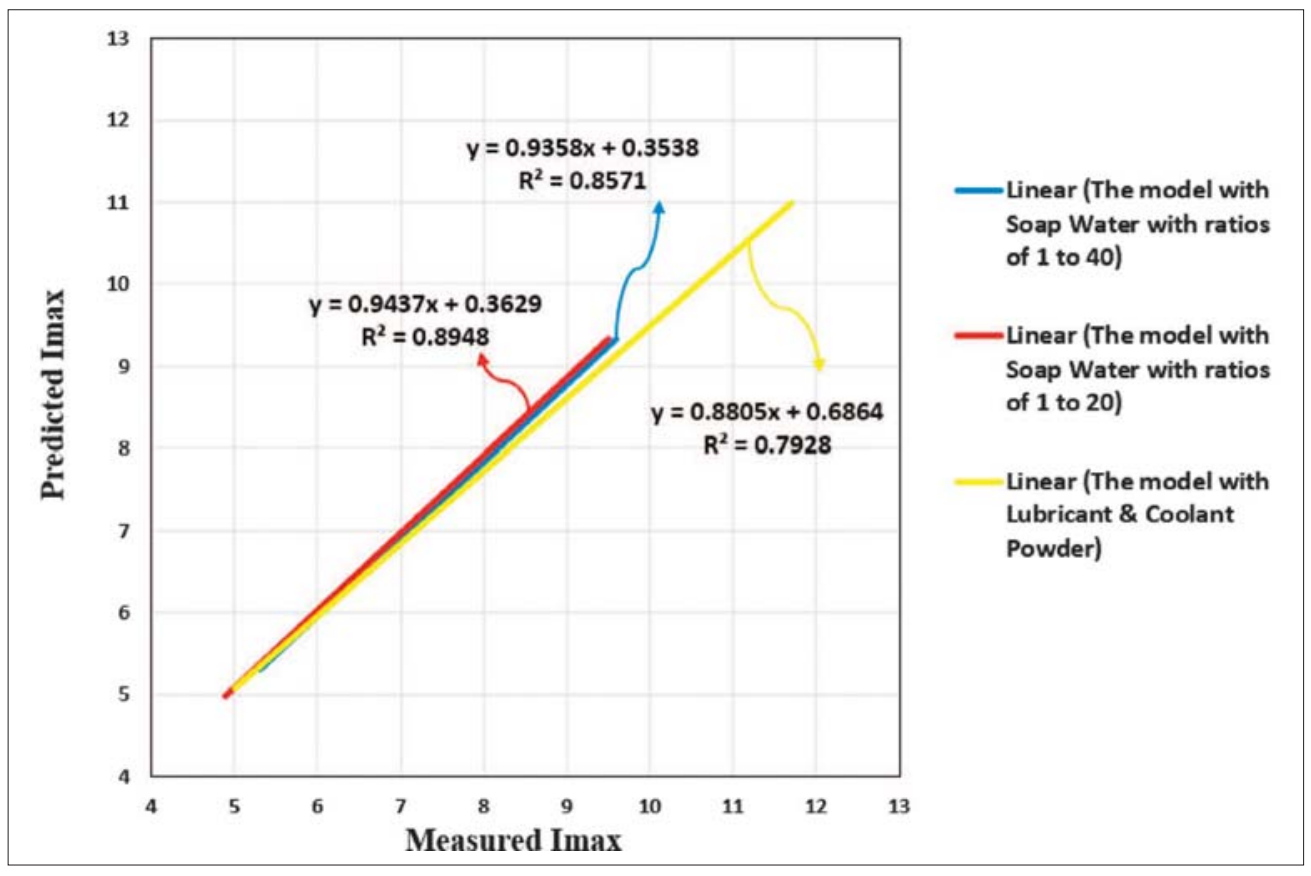

Figure 5: The correlation between the measured and anticipated electrical current for the three models using RBF 
the conducted simulations for the soap water with a ratio of 1 to 40, soap water with a ratio of 1 to 20, and lubricant and coolant powder, respectively.

After the modelling based on the experimental results obtained under three different fluids, the simulated models are rated according to the simple rating method to determine the best simulated model for each of the desired fluids (Zorlu et al., 2008). The obtained results are provided in Tables 8 to $\mathbf{1 0}$.

According to Tables 8 to 10 and based on the results obtained from the simulated models, model 8 with a rating of 54 has the best simulation of the maximum consumed electrical current in accordance with the results of the cutting machine with the soap water fluid with a ratio of 1 to 40 . Additionally, model 8 with a rating of 54 has the best anticipation and simulation performance for the maximum consumed electrical current based on the results of the cutting machine with the soap water fluid with a ratio of 1 to 20 and lubricant and coolant powder.

It is worth mentioning that according to the results obtained from the analyses and simulations conducted in this study, it is obvious that in the most optimal and desired models for anticipating the maximum electrical current consumed by the cutting machine, spread is equal to 1.5 and the number of neurons in the hidden network is equal to 100 for the results obtained using all of the three fluids used in the experiment. Furthermore, generally it can be said that most models with 90 neurons have minimum performance.

In the final step, by determining a structure similar to the RBF artificial neural network for the three fluids, once more data was randomly and separately evaluated for each fluid. The results obtained for each of the models are provided in Table $\mathbf{1 1}$ and Figure 5 for each fluid.

According to the results of Table 11, it is clear that the structure of the RBF neural network is very optimal and appropriate for the experimental data analysis based on three different fluids, and the neural network's performance indices in each of the three models have acceptable and proper values. According to Figure 5, it is worth noting that the proposed model showed the highest reduction in the maximum electrical current consumed by the cutting machine under the lubricant and coolant powder compared to the other two fluids. Furthermore, the soap water fluids with ratios of 1 to 40 and 20 had the highest reduction in the consumed electrical current, respectively.

\section{Discussions and Conclusions}

- Nowadays, with the growth of the construction industry and a significant increase in housing demand, dimension stones play a significant role in this industry as one of the most important construction materials. Therefore, investors in the sectors of quarries and stone processing factories look for ways to increase the efficiency and quality of the produced products. Therefore, the appropriate identification and understanding of the production process and cutting process of dimension stones are the most influential factors in economic efficiency and the reduction and optimization of the maximum electrical current consumed by the cutting machines. One of the influential factors in the reduction of the maximum electrical current consumed by the cutting machines is the correct selection and application of the coolant and the lubricant fluids. Thus, in this study by reviewing three different fluids, the machine's cutting process and the effect of each of these fluids on the consumed electrical current are investigated and measured. In order to conduct laboratory experiments, 10 granite stone samples were collected from Iranian quarries and after preparation of the samples, 160 tests were conducted for each fluid and a total of 480 laboratory tests were done for the three fluids. According to the conducted tests, 4 important and influential physical and mechanical parameters of stones included the uniaxial compressive strength, Mohs hardness, Schimazek's F-abrasiveness factors and Young modulus, and the maximum consumed electrical current were determined and measured based on the machine's two different operational parameters, including Fr and Dc. In the final step, the results measured based on the analytical and statistical methods and also the RBF neural network as one of the most practical intelligent methods were evaluated and analyzed. The results obtained from this study can be explained and the required suggestions are provided as follows:

- According to the outputs of the regression method, the multivariate linear regression method as one of the most practical analytical and statistical methods had a high ability in analyzing the data obtained from each test. The results of the multivariate linear regression method show the superiority of the lubricant and coolant powder over the other two fluids for reducing the electrical current consumed by the cutting machine.

- In another analysis by the RBF neural networks, it was determined that this kind of network had a very optimal efficiency in providing an optimal model for predicting the maximum consumed electrical current and the analysis of results. In addition, the lubricant and coolant powder and two types of soap water with ratios of 1 to 40 and 1 to 20 had the highest effect on the reduction of the maximum consumed electrical current, respectively.

- Consequently, it can be concluded that based upon the obtained results and the properties of the coolant and lubricant fluids, the viscosity of fluids plays a key role in reducing the electrical current consumed. The lubricant and coolant powder as the 
best fluid had the viscosity $=1.839(\mathrm{mPa} \cdot \mathrm{s})$ compared to the soap water with ratios of 1 to 40 and 1 to 20 with 0.9851 and $0.9754(\mathrm{mPa} \cdot \mathrm{s})$, respectively. It roots in the fact that, in order to reduce thermal stresses in the cutting process of hard rocks, the effect of lubricant had superiority in comparison with the effect of coolant.

- It is worth noting that based on the conducted studies, it was determined that in both analytical methods, the obtained results are the same and confirm each other. In other words, the statistical results are appropriately matched with the results of the intelligent method used in this research, and it means that the process of analysis and study of results proceeded in a correct and accurate path.

- By determining the most appropriate fluid to reduce the consumed electrical current, the obtained results could have a significant role in enhancing the efficiency and quality of the produced products for granite stone as a hard rock in quarries and rock cutting factories.

- Finally, it is suggested that the results obtained from this research are studied and analyzed with other analytical methods and meta-heuristic and hybrid algorithms. In addition, the relationship analysis between coolant fluids and tool consumption for improving the efficiency and quality of the manufactured product are worth studying.

\section{References}

Antoljak, D., Kuhinek, D., Korman, T., \& Kujundžić, T. (2018): Dependency of Specific Energy of Rock Cutting on Specific Drilling Energy. Rudarsko-geološko-naftni zbornik (The Mining- Geological-Petroleum Engineering Bulletin), 33, 3, 23-32.

Akhyani, M., Sereshki, F., \& Mikaeil, R. (2018): An Investigation of the Effect of Toughness and Brittleness Indexes on Ampere Consumption and Wear Rate of a Circular Diamond Saw. Rudarsko-geološko-naftni zbornik (The Mining- Geological-Petroleum Engineering Bulletin), 33, 4, $85-92$.

Aryafar, A., Mikaeil, R., Haghshenas, S. S., \& Haghshenas, S. S. (2018): Application of metaheuristic algorithms to optimal clustering of sawing machine vibration. Measurement, 124, 20-31.

Armaghani, D. J., Hasanipanah, M., \& Mohamad, E. T. (2016): A combination of the ICA-ANN model to predict air-overpressure resulting from blasting. Engineering with Computers, 32, 1, 155-171.

Balci, C., \& Tumac, D. (2012): Investigation into the effects of different rocks on rock cuttability by a V-type disc cutter. Tunnelling and Underground Space Technology, 30, 183-193.

Bai, S., Hua, Q., Elwert, T., \& Wang, Q. (2018): Development of a method based on MADM theory for selecting a suitable cutting fluid for granite sawing process. Journal of Cleaner Production, 185, 211-229.
Boubekri, N., \& Shaikh, V. (2015): Minimum quantity lubrication (MQL) in machining: Benefits and drawbacks. Journal of Industrial and Intelligent Information, 3, 3, 205-209.

Careddu, N., Siotto, G., \& Marras, G. (2017a): The crisis of granite and the success of marble: errors and market strategies. The Sardinian case. Resources Policy, 52, 273-276.

Careddu, N., Perra, E. S., \& Masala, O. (2017b): Diamond wire sawing in ornamental basalt quarries: technical, economic and environmental considerations. Bulletin of Engineering Geology and the Environment, 1-12.

Copur, H., Bilgin, N., Balci, C., Tumac, D., \& Avunduk, E. (2017): Effects of different cutting patterns and experimental conditions on the performance of a conical drag tool. Rock Mechanics and Rock Engineering, 50, 6, 1585-1609.

Darbor, M., Faramarzi, L., \& Sharifzadeh, M. (2017): Performance assessment of rotary drilling using non-linear multiple regression analysis and multilayer perceptron neural network. Bulletin of Engineering Geology and the Environment, 1-13.

Dormishi, A., Ataei, M., Khaloo Kakaie, R., Mikaeil, R., \& Shaffiee Haghshenas, S. (2018): Performance evaluation of gang saw using hybrid ANFIS-DE and hybrid ANFIS-PSO algorithms. Journal of Mining and Environment, 1-16.

Er, M. J., Wu, S., Lu, J., \& Toh, H. L. (2002): Face recognition with radial basis function (RBF) neural networks. IEEE transactions on neural networks, 13, 3, 697-710.

Fathabadi, H. S., \& Khodaei, M. (2012): Reliability evaluation of network flows with stochastic capacity and cost constraint. International Journal of Mathematics in Operational Research, 4, 4, 439-452.

Faradonbeh, R. S., Armaghani, D. J., Monjezi, M., \& Mohamad, E. T. (2016): Genetic programming and gene expression programming for flyrock assessment due to mine blasting. International Journal of Rock Mechanics and Mining Sciences, 88, 254-264.

Faradonbeh, R. S., \& Taheri, A. (2018): Long-term prediction of rockburst hazard in deep underground openings using three robust data mining techniques. Engineering with Computers, 1-17.

Feng, X., Li, S., Yuan, C., Zeng, P., \& Sun, Y. (2018): Prediction of Slope Stability using Naive Bayes Classifier. KSCE Journal of Civil Engineering, 22, 3, 941-950.

Hoseinian, F. S., Faradonbeh, R. S., Abdollahzadeh, A., Rezai, B., \& Soltani-Mohammadi, S. (2017): Semi-autogenous mill power model development using gene expression programming. Powder Technology, 308, 61-69.

International Society for Rock Mechanics. (1981): Rock characterization testing \& [and] monitoring: ISRM suggested methods. Pergamon Press.

Ivšinović, J. (2018): The cost analysis of the separation of produced formation water from the hydrocarbon reservoir using the example of the Upper Miocene sandstone deposits of the Sava Depression. Rudarsko-geološko-naftni zbornik (The Mining- Geological-Petroleum Engineering Bulletin), 33, 1, 35-43.

Khandelwal, M., Armaghani, D. J., Faradonbeh, R. S., Ranjith, P. G., \& Ghoraba, S. (2016): A new model based on gene 
expression programming to estimate air flow in a single rock joint. Environmental Earth Sciences, 75, 9, 739.

Khandelwal, M., Armaghani, D. J., Faradonbeh, R. S., Yellishetty, M., Majid, M. Z. A., \& Monjezi, M. (2017): Classification and regression tree technique in estimating peak particle velocity caused by blasting. Engineering with Computers, 33, 1, 45-53.

Karayiannis, N. B., \& Behnke, S. (2018): New radial basis neural networks and their application in a large-scale handwritten digit recognition problem. In Recent advances in artificial neural networks (pp. 61-116). CRC Press.

Looney, C. G. (1996): Advances in feedforward neural networks: demystifying knowledge acquiring black boxes. IEEE Transactions on Knowledge and Data Engineering, 8, 2, 211-226.

Mahdevari, S., Shahriar, K., Sharifzadeh, M., \& Tannant, D. D. (2017): Stability prediction of gate roadways in longwall mining using artificial neural networks. Neural Computing and Applications, 28, 11, 3537-3555.

Manouchehrian, A., Gholamnejad, J., \& Sharifzadeh, M. (2014): Development of a model for analysis of slope stability for circular mode failure using genetic algorithm. Environmental Earth Sciences, 71, 3, 1267-1277.

Mikaeil, R., Sohrabian, B., \& Ataei, M. (2018a): The study of energy consumption in the dimension stone cutting process. Rudarsko-geološko-naftni zbornik (The Mining- Geological-Petroleum Engineering Bulletin), 33, 4, 71-71.

Mikaeil, R., Ozcelik, Y., Ataei, M., \& Shaffiee Haghshenas, S. (2016): Application of harmony search algorithm to evaluate performance of diamond wire saw. Journal of Mining and Environment.

Mikaeil, R., Haghshenas, S. S., Ozcelik, Y., \& Gharehgheshlagh, H. H. (2018b): Performance evaluation of adaptive neuro-fuzzy inference system and group method of data handling-type neural network for estimating wear rate of diamond wire saw. Geotechnical and Geological Engineering, 1-13.

Mikaeil, R., Haghshenas, S. S., Haghshenas, S. S., \& Ataei, M. (2018c): Performance prediction of circular saw machine using imperialist competitive algorithm and fuzzy clustering technique. Neural Computing and Applications, 29, 6, 283-292.

Mikaeil, R., Shaffiee Haghshenas, S., Ozcelik, Y., \& Shaffiee Haghshenas, S. (2017): Development of Intelligent Systems to Predict Diamond Wire Saw Performance. Soft Computing in Civil Engineering, 1, 2, 52-69.

Mirjalili, S. (2019): Evolutionary Radial Basis Function Networks. In Evolutionary Algorithms and Neural Networks (pp. 105-139). Springer, Cham.

Mohammadi, J., Ataei, M., Kakaei, R. K., Mikaeil, R., \& Haghshenas, S. S. (2018): Prediction of the Production Rate of Chain Saw Machine using the Multilayer Perceptron (MLP) Neural Network. Civil Engineering Journal, 4, 7, 1575-1583.

Ocak, İ., Seker, S. E., \& Rostami, J. (2018). Performance prediction of impact hammer using ensemble machine learn- ing techniques. Tunnelling and Underground Space Technology, 80, 269-276.

Rad, M. Y., Haghshenas, S. S., Kanafi, P. R., \& Haghshenas, S. S. (2012): Analysis of Protection of Body Slope in the Rockfill Reservoir Dams on the Basis of Fuzzy Logic. In IJCCI (pp. 367-373).

Rad, M. Y., Haghshenas, S. S., \& Haghshenas, S. S. (2014): Mechanostratigraphy of cretaceous rocks by fuzzy logic in East Arak, Iran. In The 4th International Workshop on Computer Science and Engineering-Summer, WCSE.

Sabzi, H. Z., King, J. P., Gard, C. C., \& Abudu, S. (2016): Statistical and analytical comparison of multi-criteria decision-making techniques under fuzzy environment. Operations Research Perspectives, 3, 92-117.

Sabzi, H. Z., King, J. P., \& Abudu, S. (2017): Developing an intelligent expert system for streamflow prediction, integrated in a dynamic decision support system for managing multiple reservoirs: A case study. Expert Systems with Applications, 83, 145-163.

Salemi, A., Mikaeil, R., \& Haghshenas, S. S. (2018): Integration of finite difference method and genetic algorithm to seismic analysis of circular shallow tunnels (Case study: Tabriz urban railway tunnels). KSCE Journal of Civil Engineering, 22, 5, 1978-1990.

Strumiłło, P., \& Kamiński, W. (2003): Radial basis function neural networks: theory and applications. In Neural Networks and Soft Computing (pp. 107-119). Physica, Heidelberg.

Sharifzadeh, M. (2017): Multivariate Estimation of Rock Mass Characteristics Respect to Depth Using ANFIS Based Subtractive Clustering-Khorramabad-Polezal Freeway Tunnels. Journal of Engineering Geology, 10, 4, 3793-3808.

Tumac, D., Avunduk, E., Copur, H., \& Balci, C. (2016): Investigation of the effect of textural properties towards predicting sawing performance of diamond wire machines. Rock Mechanics and Rock Engineering: From the Past to the Future, 211.

Tumac, D., Copur, H., Balci, C., Er, S., \& Avunduk, E. (2018): Investigation into the Effects of Textural Properties on Cuttability Performance of a Chisel Tool. Rock Mechanics and Rock Engineering, 51, 4, 1227-1248.

Ucun, I., Aslantas, K., Buyuksagis, S. and Tasgetiren, S. (2012): Effect of coolant liquids on cutting process using diamond segmented disc of natural stones. Journal of Mechanical Engineering Science, Proceed, 227, 10, 2315-2327.

Yingwei, L., Sundararajan, N., \& Saratchandran, P. (1998): Performance evaluation of a sequential minimal radial basis function (RBF) neural network learning algorithm. IEEE Transactions on neural networks, 9, 2, 308-318.

Zorlu, K., Gokceoglu, C., Ocakoglu, F., Nefeslioglu, H. A., \& Acikalin, S. (2008): Prediction of uniaxial compressive strength of sandstones using petrography-based models. Engineering Geology, 96, 3-4, 141-158. 